Nat. Hazards Earth Syst. Sci., 10, 865-873, 2010

www.nat-hazards-earth-syst-sci.net/10/865/2010/

(C) Author(s) 2010. This work is distributed under

the Creative Commons Attribution 3.0 License.

\title{
Technical Note: Implementation of a geodatabase of published and unpublished data on the catastrophic Vaiont landslide
}

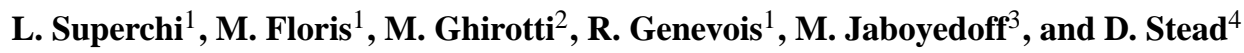 \\ ${ }^{1}$ Dept. of Geosciences, University of Padova, Italy \\ ${ }^{2}$ Dept. of Earth and Geo-Environmental Sciences, University of Bologna, Italy \\ ${ }^{3}$ Institute of Geomatics and Risk Analysis (IGAR), University of Lausanne, Switzerland \\ ${ }^{4}$ Dept. of Earth Sciences, Simon Fraser University, Burnaby, Canada
}

Received: 9 November 2009 - Revised: 5 March 2010 - Accepted: 23 March 2010 - Published: 20 April 2010

\begin{abstract}
On 9 October 1963 a catastrophic landslide suddenly occurred on the southern slope of the Vaiont dam reservoir. A mass of approximately 270 million $\mathrm{m}^{3}$ collapsed into the reservoir generating a wave that overtopped the dam and hit the town of Longarone and other villages nearby. Several investigations and interpretations of the slope collapse have been carried out during the last 45 years, however, a comprehensive explanation of both the triggering and the dynamics of the phenomenon has yet to be provided.

In order to re-evaluate the currently existing information on the slide, an electronic bibliographic database and an ESRI-geodatabase have been developed. The chronology of the collected documentation showed that most of the studies for re-evaluating the failure mechanisms were conducted in the last decade, as a consequence of knowledge, methods and techniques recently acquired. The current contents of the geodatabase will improve definition of the structural setting that influenced the slide and led to the the propagation of the displaced rock mass.

The objectives, structure and contents of the ebibliography and Geodatabase are indicated, together with a brief description on the possible use of the alphanumeric and spatial contents of the databases.
\end{abstract}

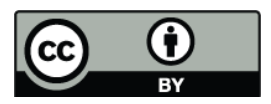

Correspondence to: L. Superchi

(laura.superchi@unipd.it)

\section{Introduction}

The Vaiont landslide (Fig. 1) is considered to represent a natural laboratory in which to investigate failure mechanisms and evolution in large rock masses. The catastrophic 1963 landslide demonstrated the paramount importance of detailed geologic investigations. Geological, structural, geomorphological, hydrogeological and geomechanical features at Vaiont are being re-analysed using new methods and techniques, such as photogrammetric analyses, terrestrial and aerial laser scanning data acquisition and interpretation, topographic DEM analyses, rock mass characterisation and numerical 3-D modelling. Despite that, to date, considerable research has been carried out, the Vaiont landslide continues to provide an engineering case study of both high scientific interest and significant technological challenges. The first detailed geological studies were carried out by Giudici and Semenza (1960), who emphasized the existence of a huge prehistoric landslide on the reservoir mountainside, which could be remobilized in the presence of the planned reservoir. Subsequently, following nearly 3 years of intermittent and slow slope movements, a rock mass of about 270 million $\mathrm{m}^{3}$ suddenly collapsed into the reservoir, generating a huge wave that hit the town of Longarone and other villages, killing almost 2000 people. Several interpretations of this event have been proposed during the last 45 years (e.g., Müller, 1964, 1987a, b; Selli et al., 1964; Skempton, 1966; Hendron and Patton, 1985; Semenza, 2000). Some authors have attempted to explain the sudden acceleration of the mass in some cases suggesting varied mechanisms (Nonveiller, 1992; Tika and Hutchinson, 1999; Kilburn and Petley, 2003). Nevertheless, a comprehensive explanation of both the triggering and

Published by Copernicus Publications on behalf of the European Geosciences Union. 


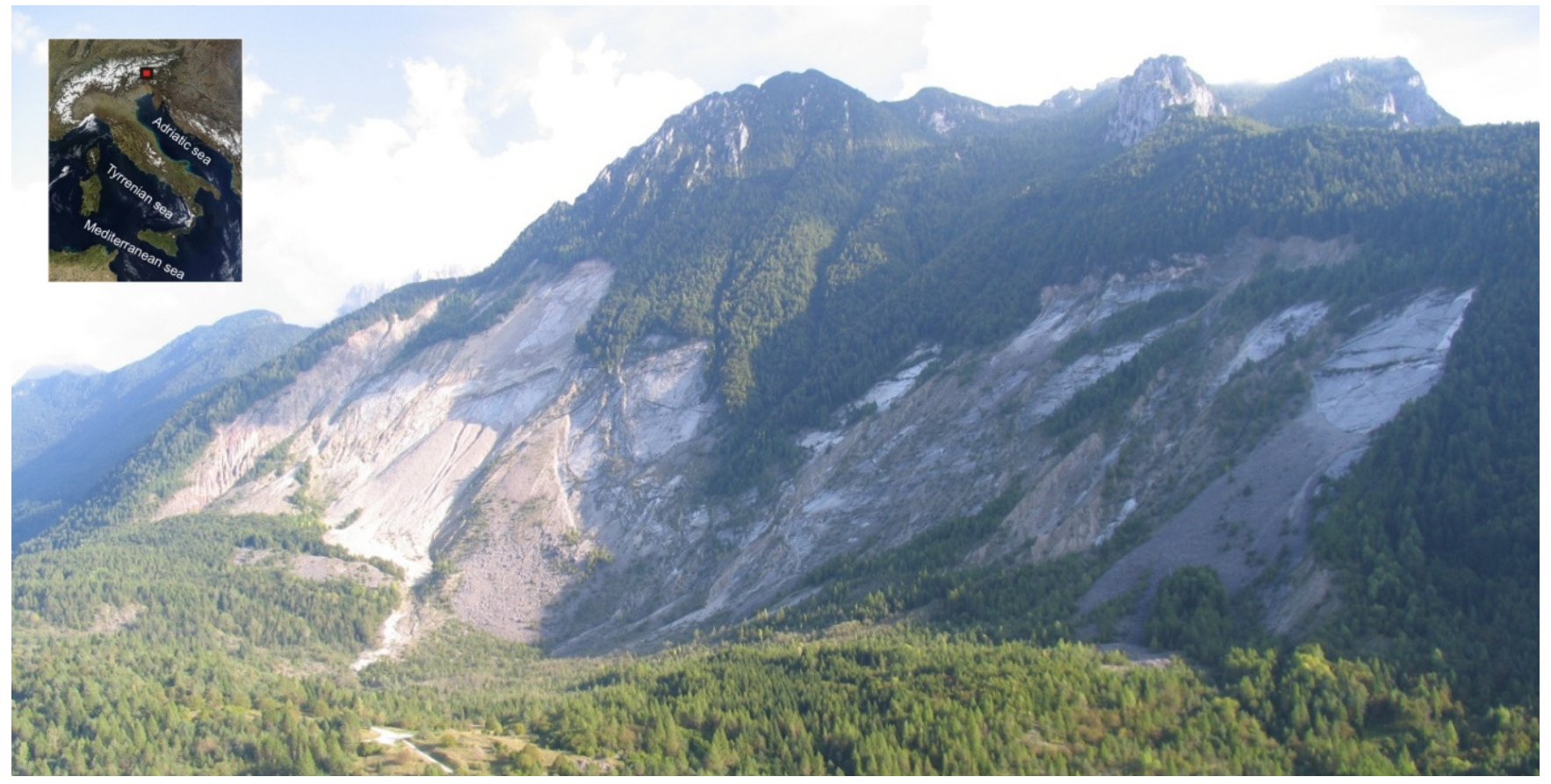

Fig. 1. Panoramic view of the slip surface of the Vaiont landslide that occurred on 9 October 1963.

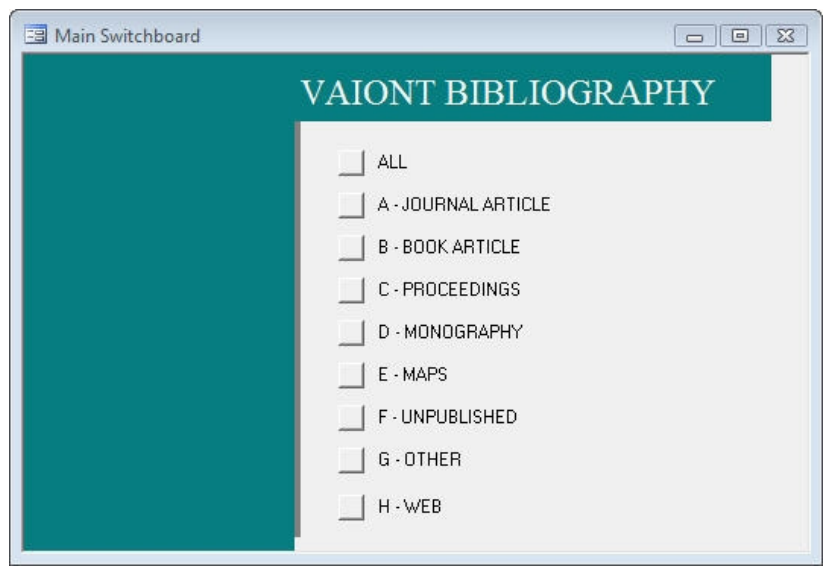

Fig. 2. Main switchboard of the electronic bibliographic database.

dynamics of the phenomenon still remains elusive. The most comprehensive work to date was undertaken by Hendron and Patton (1985) who concluded by emphasising the need for continued and more in depth research. A complete review of the most important papers related to the 1963 landslide is presented in Genevois and Ghirotti (2005).

In this paper, the authors describe the structure and contents of recently developed alphanumeric and spatial databases on the Vaiont landslide. The potential use of these databases in a re-evaluation of the landslide mechanics and dynamics, utilizing current knowledge on rock slides and state-of-the-art methods of data acquisition and numerical modelling is briefly discussed. In addition, all the references to published documents, theses and unpublished technical reports on the Vaiont landslide have been organized and stored in a database and are provided as Supplementary Material (http://www.nat-hazards-earth-syst-sci.net/10/ 865/2010/nhess-10-865-2010-supplement.pdf).

\section{The electronic-bibliographic database}

The catastrophic Vaiont landslide has stimulated and generated a significant volume of research, however, most of the available documentation owing to the time at which it was produced is in a non-electronic format. Hence, the first extremely important step was to scan digitally all documentation on the landslide. All the references to published documents, theses, unpublished technical reports and maps on landslide, have subsequently been organized and stored in a database using MS Access software.

The references are contained in a main table and are divided, on the basis of document typology, into Journal article (A), Book article (B), Proceedings (C), Monography (D), Maps (E), Unpublished (F), Other (G), and Web (H), (Fig. 2). Input masks to queries that extract the relevant information for each typology, were created to help in storing and visualizing data (Fig. 3a, b). In order to facilitate data retrieval, all the masks include local (field "LOCAL LINK") and/or internet (field "LINK") connections to documents available in a local directory or on a web site. A further important database field is termed "NOTE" where the presence in the 

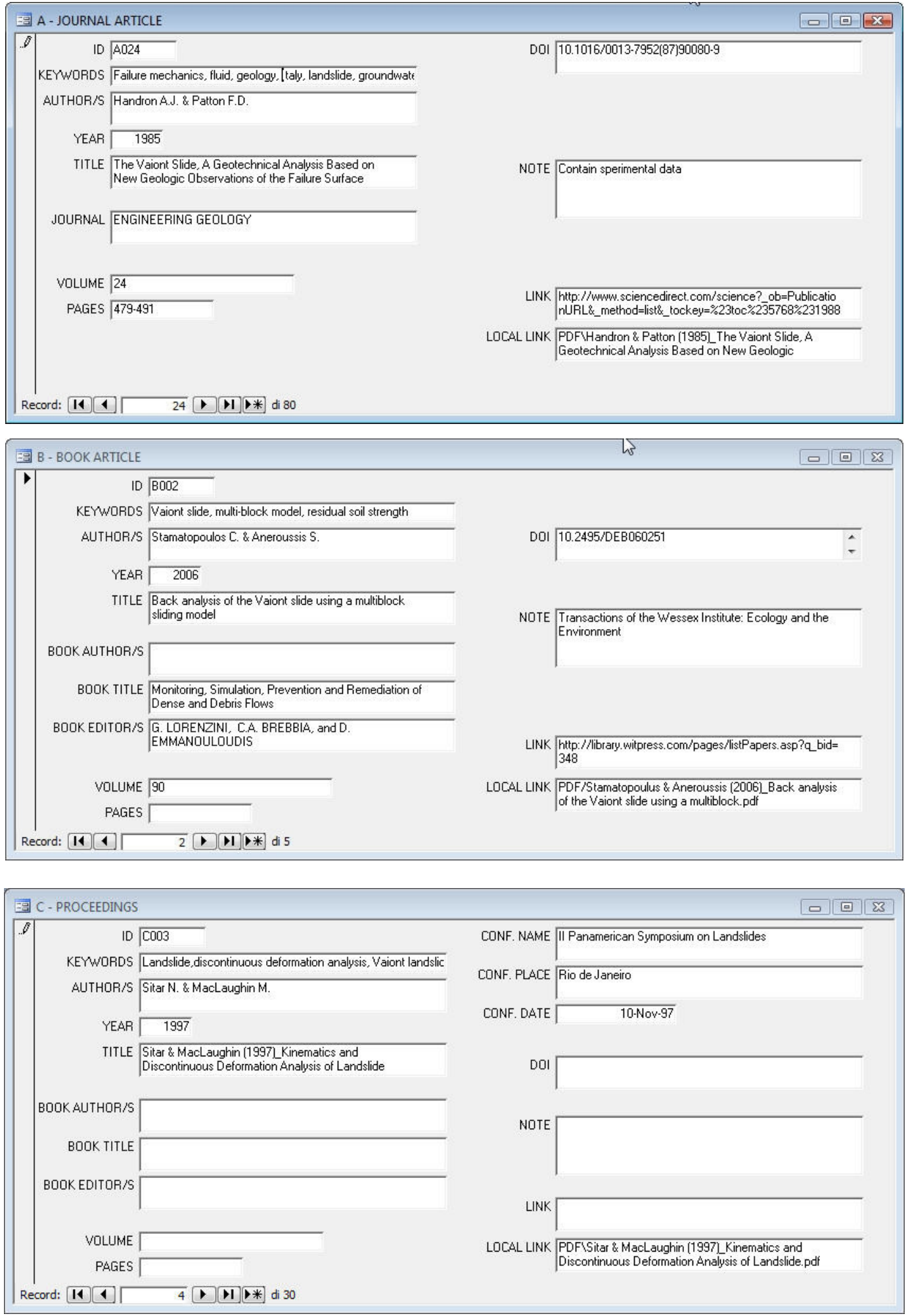

Fig. 3a. Input masks created for inserting and visualizing references to journal articles (A), Book articles (B), Proceedings (C). Input mask of Monographs (D) is similar to that for Book article (B). 


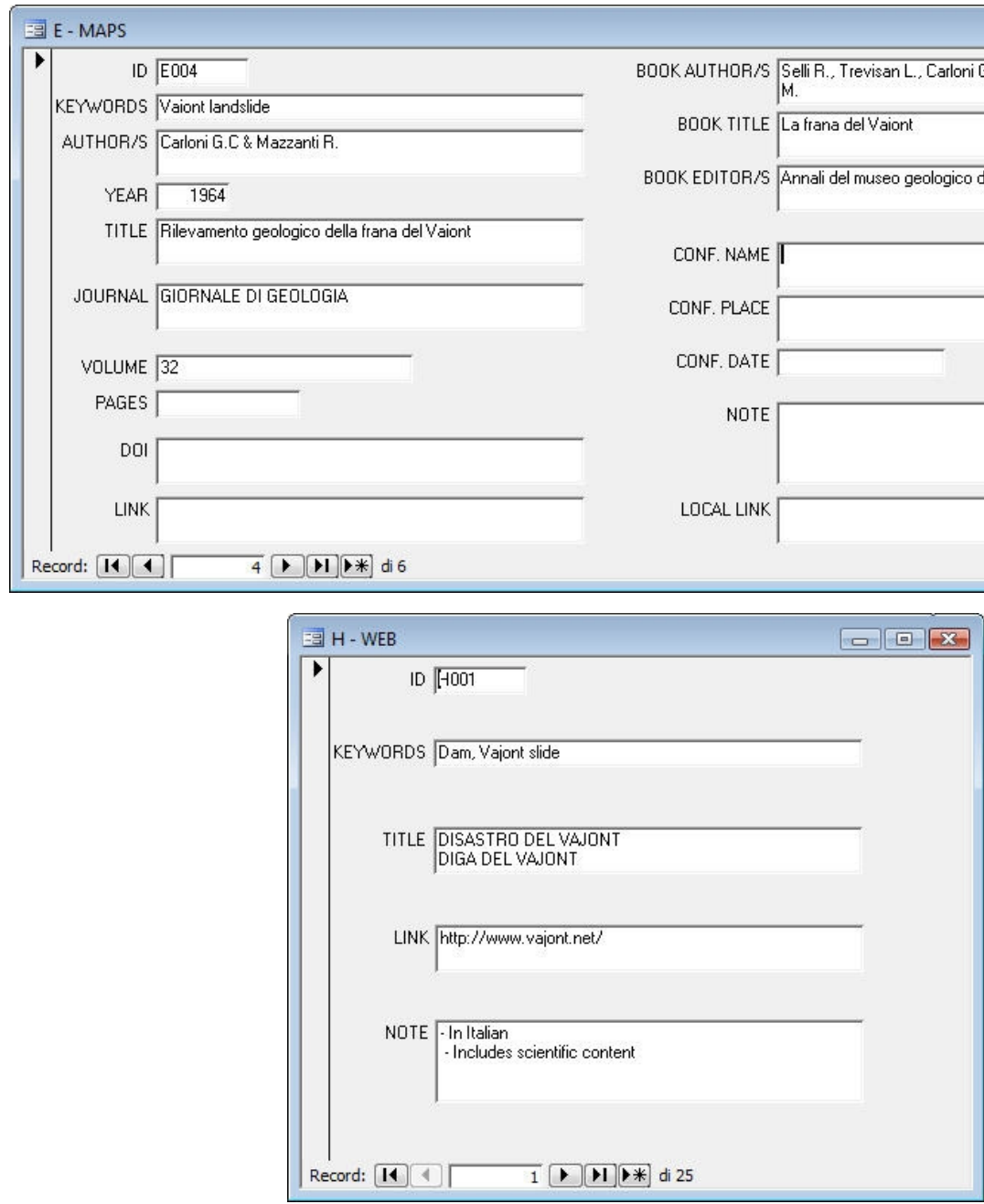

Fig. 3b. Input masks created for inserting and visualizing references to maps $(\mathrm{E})$ and web site (H). Input mask of unpublished reports (F) and other (newspaper articles, conference presentations and relevant material) $(\mathrm{G})$ are similar to that for maps (E).

document of data from geological and geomechanical surveys, geotechnical data from laboratory tests and scientific contents, is reported (Fig. 4).

The database currently contains references to 80 journal articles, 5 book articles, 51 monographs, 6 thematic maps, 30 conference proceedings, 5 unpublished reports, 25 web sites and 13 documents classified as "Other" (newspaper articles, conference presentations and relevant material). The chronology of the documentation shows a relatively high production immediately after the landslide (Fig. 5). After a period (1970-1979) of apparent decreasing interest, the documentation increased during 1980-1999, in a large part due to an International Conference on the Vaiont landslide, organized by E. Semenza at the University of Ferrara (Italy) on September 1986. Of note is that most of the documentation, especially journal articles and monographs, have been produced in the last 10 years, as a consequence of both new methods and techniques available for numerical analyses and of the large increase in the electronic tools available for publishing and sharing scientific papers.

\section{Structure and contents of the geodatabase}

A geodatabase is a database designed to store, query, and manipulate geographic information and spatial data. Different types of spatial data, such as vector and raster datasets, and their attributes and location can be stored. In addition, tables and relationships between data can be included. The geodatabase forms the first step in implementing a Geographic Information System (GIS) organized to allow data collection, management and visualization of large slope instabilities and contributing factors (Chacón et al., 2006; Giardino et al., 2004). Vector datasets consist of geometrical primitives such as points, lines, curves and shapes or polygon(s), which are all based on mathematical equations and represent territorial 

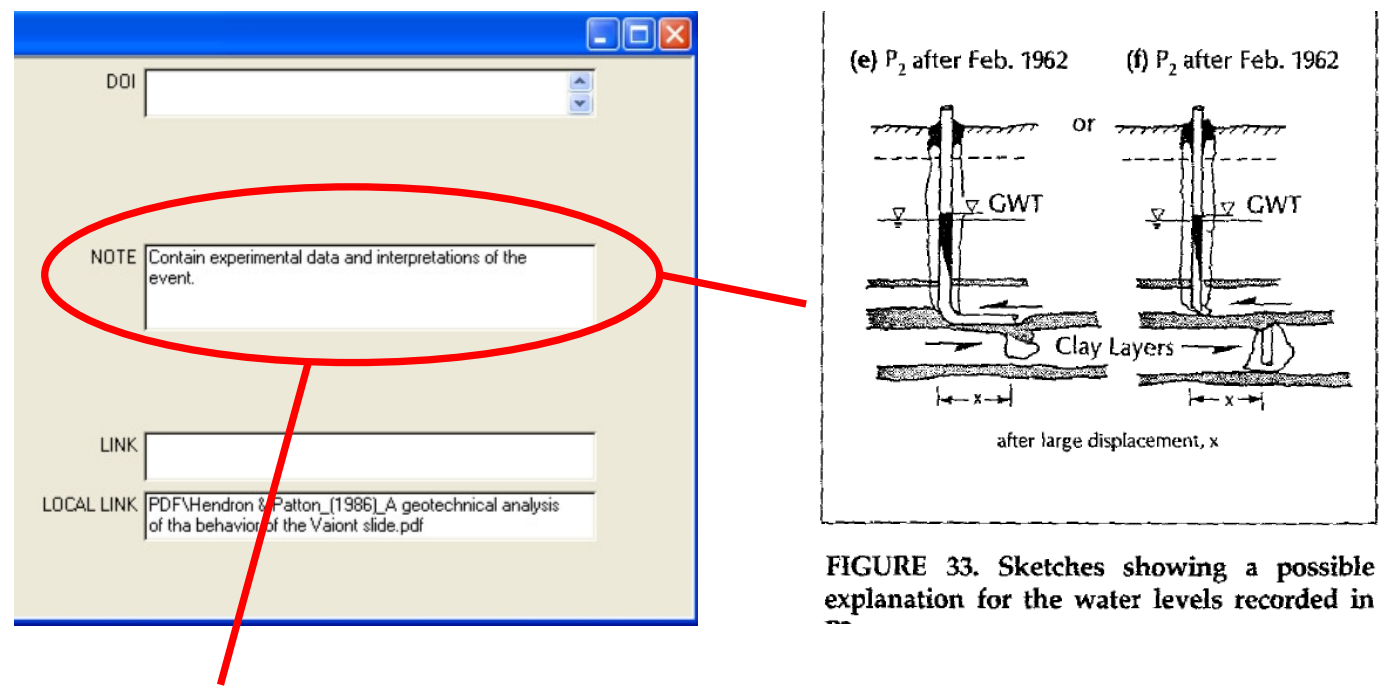

FIGURE 33. Sketches showing a possible explanation for the water levels recorded in

$\begin{array}{cccc}\begin{array}{c}\text { Sample } \\ \text { No. }\end{array} & \begin{array}{c}\text { Liquid } \\ \text { Limit }\end{array} & \begin{array}{c}\text { Ptastic } \\ \text { Umit }\end{array} & \begin{array}{c}\text { Plasticity } \\ \text { index }\end{array} \\ 12-6 & 72 & 23 & 49 \\ 12-6 \mathrm{~A} & 35 & 19 & 16 \\ 18-6 & 49 & 27 & 22 \\ 18-6 \mathrm{~A} & 39 & 20 & 19 \\ 18-8 & 45 & 32 & 13 \\ 18-9 & 37 & 25 & 12 \\ 18-9 \mathrm{~A} & 48 & 33 & 15 \\ 18-17 & 38 & 25 & 13\end{array}$

\section{Descriptive Notes}

Clay in debris about $4 \mathrm{~m}$ above faifure plane

Clay on failure plane 130 m from 12-6)

Clay on failure plain at scarp

Clayey debris on rock

surface near scarp

Clay in-situ forms

failure plane above

Clay in-situ forms

adjacent failure plane

Clay in-situ on failure plane

Clay in-situ forms

failure plane below

Fig. 4. Example of data and interpretations reported in the field NOTE of the e-bibliography. Sketches from Hendron and Patton (1986).

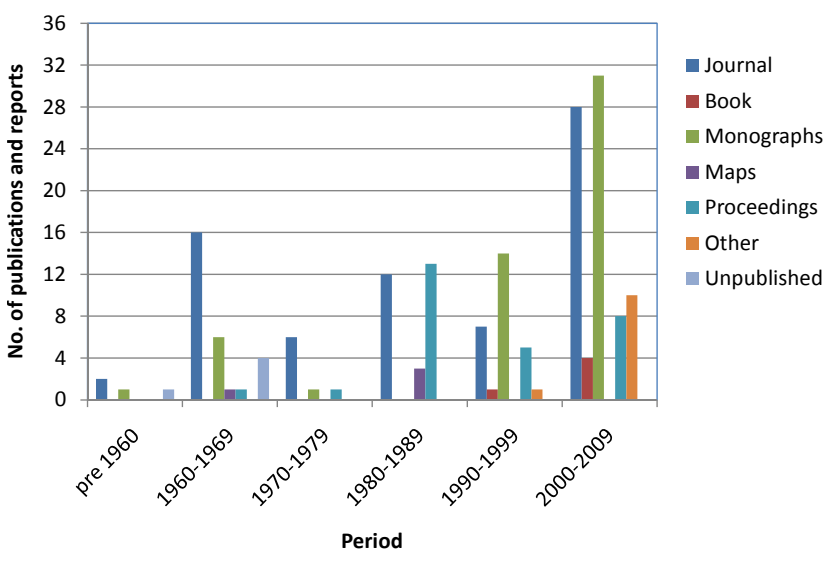

Fig. 5. Chronology of the documentation on the Vaiont landslide.

data (geomechanical stations, faults, lithology, etc.). A raster dataset is a data structure representing a generally rectangular grid of pixels, or points of colour. In the GIS, raster datasets of varying formats are usually used to represent continuous territorial data (DEM, slope, etc.) and to perform simple to complex analyses.

The Vaiont geodatabase was implemented using ESRI ArcGIS Desktop 9.3 software and comprises:

1. Feature classes are homogeneous collections of common features, each having the same spatial representation, such as points, lines or polygons.

2. Feature datasets are objects that allow to group together related feature classes.

3. Tables are data collection of rows (records) and columns (attributes) used to store non-spatial data.

4. Relationship classes manage associations between objects in one table and objects in another. Rules to relate feature to feature (spatial relationships), row to row (non spatial relationships), and feature to row (spatial to non spatial relationships), are stored.

5. Raster datasets are grid-based representations of spatial data. 
6. Raster catalogues are objects that allow efficient storage and management of multiple spatially-related raster datasets.

7. Terrain datasets are surfaces that represent threedimensional space. They use measurements (stored as feature classes) and rules to generate triangular irregular network (TIN) pyramids to represent elevation. From the terrain dataset, it is possible to obtain both a vectorial-based elevation model (TIN) and a rasterbased Digital Elevation Model (DEM).

Currently, the Vaiont geodatabase contains the following data.

- Vector datasets representing the attitude of strata, faults, lithology, and geological sections; digitized from preand post-landslide geological maps at 1:5000 scale (Rossi and Semenza, 1965).

- Vector datasets representing geognostic boreholes from Broili (1959) and geophysical investigation from Caloi (1960), and their attributes (type, depth, stratigraphy).

- Vector dataset representing geomechanical stations from past and recent surveys. Related attributes consist of rock and rock mass properties (discontinuities attributes such as orientation, size, aperture, roughness, etc., Schmidt Hammer testing, Geological Strength Index, Point Load Test, etc.) (see Table 1 for an example).

- Vector datasets representing elevation points and contour lines digitized from pre- and post-landslide topographic maps, official regional maps (CTR, Regione Friuli Venezia Giulia) and LiDAR survey.

- Raster datasets representing the Digital Elevation Model (DEM) of the area before and after the landslide. DEMs were calculated from the above mentioned topographic data.

- Raster datasets organized in a Raster Catalog, representing the aerial photos of the area before the landslide (1960).

In addition, the geodatabase contains tables of geotechnical and geomechanical properties of the rock mass inside and outside the landslide area, extracted both from the ebibliography and from current author's field surveys and laboratory tests. From simple to complex rules, stored in the Relationships classes, join and relate records in the tables to the location of the collected samples and of the geomechanical stations.

\section{Using the databases}

Modern techniques, such as photogrammetric analyses, ground-based and airborne LiDAR will greatly contribute to geometric and geomechanical rock mass characterisation. DEM-based structural analysis, performed by COLTOP-3D software (Derron et al., 2005), on available data before and after the landslide, is an important tool in identifying the structural setting that led to the failure and controlled the direction of the movement. COLTOP-3D uses a colour representation merging slope aspect and slope angle in order to obtain a unique colour code for each orientation of a topographical element (Jaboyedoff et al., 2007, 2009). Simple analysis of DEMs allow rapid identification of structural features (joints, lineaments, faults) affecting the slope (Derron et al., 2005). The 3-D surface reconstruction is extremely useful as it enables easy identification of the main morphostructural features from which joint set orientations and persistence relevant to the area of interest can be detected. Furthermore, these desktop analysis allow us to explore the area under investigation and thereby provide an aid in planning the field work and the mapping of structural data in inaccessible areas.

Seven main joint sets were detected in the pre- and post-Vaiont landslide slope using the colour coding of COLTOP-3D (Fig. 6). The joint surface pole orientations have been measured directly on the DEMs: $\mathrm{J} 1\left(160^{\circ} / 40^{\circ}\right), \mathrm{J} 2\left(238^{\circ} / 45^{\circ}\right), \mathrm{J} 3\left(300^{\circ} / 50^{\circ}\right), \mathrm{J} 4\left(345^{\circ} / 30^{\circ}\right)$, $\mathrm{J} 5\left(50^{\circ} / 20^{\circ}\right), \mathrm{J} 6\left(50^{\circ} / 70^{\circ}\right), \mathrm{J} 7\left(70^{\circ} / 45^{\circ}\right)$. Figure $6 \mathrm{a}-\mathrm{b}$ shows that one of the most important sets forming the morphostructure is J4 (light-blue), dipping northward and corresponding to the orientation of the sliding plane. The data, obtained by using COLTOP-3D, agree reasonably well with the field measurements despite the present limited number of field data (Fig. 6e).

\section{Concluding remarks}

The e-bibliography and the geodatabase represent a powerful tool to extract and select experimental data and scientific contents from the extensive documentation on the Vaiont landslide. The e-bibliography provides an important input for further scientific research not only on the Vaiont landslide but also on large rock landslides in general. Data collected in the electronic bibliographic database show that the majority of the research publications have been authored in the last decade, probably due to recent advances in both the body of knowledge on rock slides and the developments in methods and techniques for rock mass data collection and numerical analyses.

The key objective of the generated geodatabase is to store, manage, visualize and update a large number of different types of data in a central location and to make them available to the scientific community.

3-D geological, hydrogeological and geomechanical reconstruction of rock slope instabilities, such as the Vaiont 1963 event, will be more accurate and comprehensive as it will now be possible to apply new or advanced relationships 

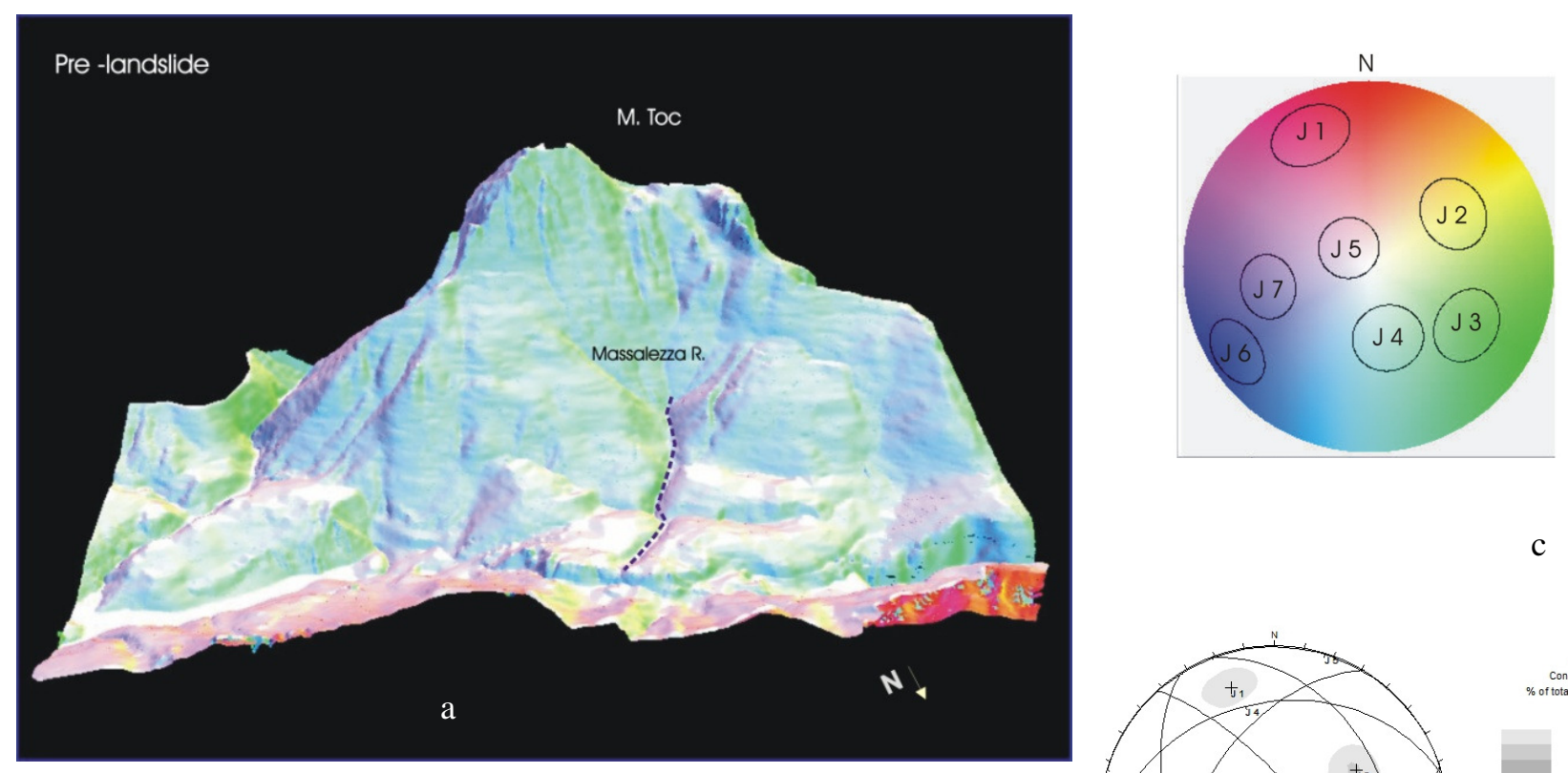

$\mathrm{c}$
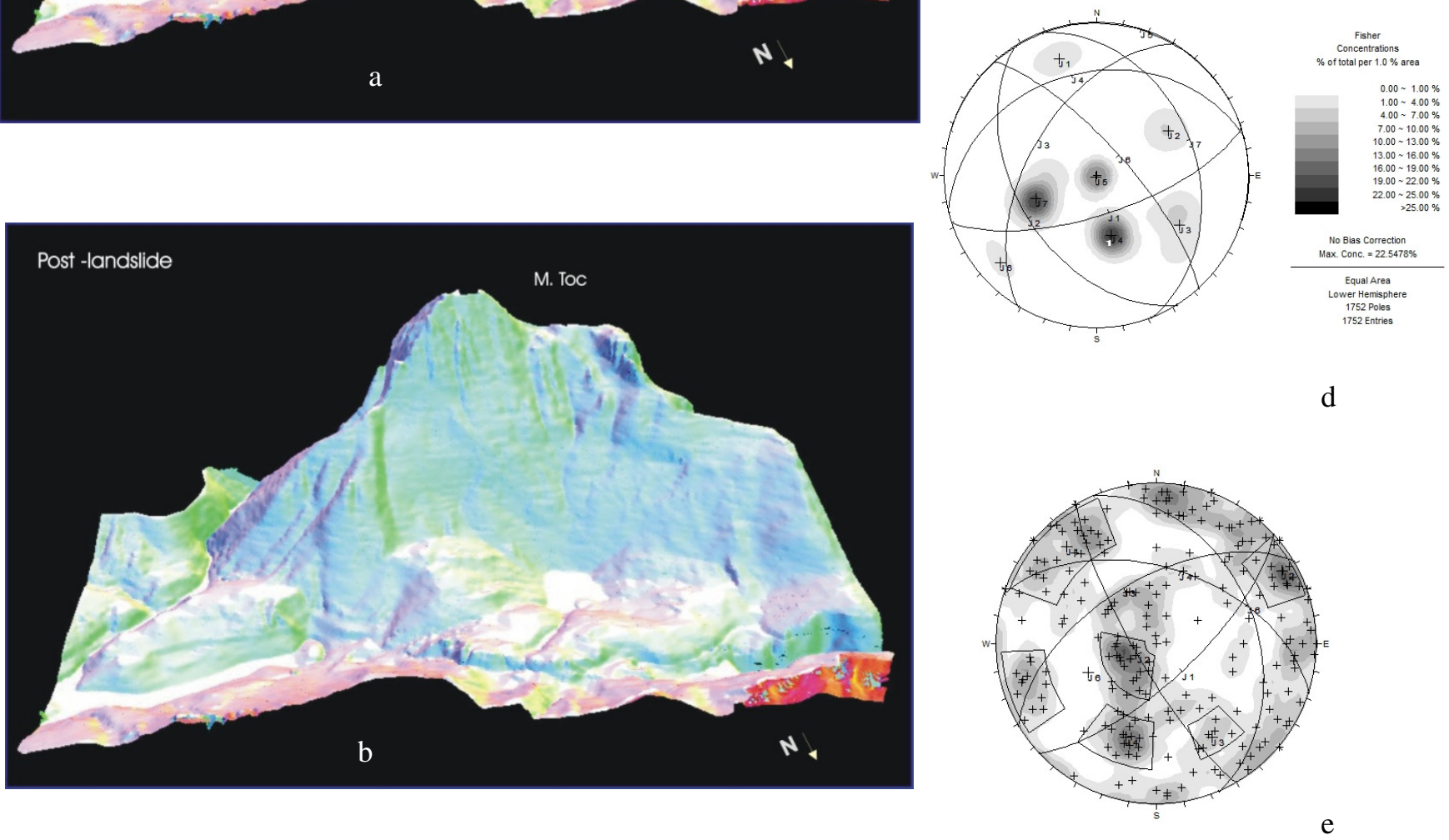

Fig. 6. COLTOP 3D analysis for the Vaiont area. In the pre- and post-landslide 3-D representation, different colours in the same area show different orientations of the structural features (faults and lineaments) (a-b). Seven morpho-structural sets were detected by COLTOP 3D, evaluated by means of the corresponding Schmidt-Lambert projection (c) and plotted using usual software (d). Obtained results were validated by comparison with the field data (e).

to collected data, to develop new methods of viewing the available information assets in a interrogative and discriminatory fashion; in summary, this will allow the leverage of all the collected data in order to optimize their potential for understanding rock slope failure mechanisms. Detailed examination of the the geodatabase can provide important data required for numerical modelling of rock slopes i.e.: i) the geological, structural and hydrogeological characteristics prior to the landslide; ii) the geomechanical characterisation of the involved rock masses; iii) the complete definition of the displacement field prior, during and after the landsliding event.

At this stage, the Vaiont geodatabase remains largely incomplete: collected data to date relating mainly to the geological setting, whereas hydrogeological and geomechanical data are somewhat limited, scanty or absent. An example of both the potential of the geodatabase and of its current 
Table 1. Geomechanical properties of the material involved in the slide, from past and current surveys. The slip surface has been placed at the bottom of the Calcare di Socchér formation (Semenza, 1965). Volumetric Joint Count (Jv), Block Size Index (Ib), Joint Roughness Coefficient (JRC), Joint Compression Strength (JCS), Geological Strength Index (GSI).

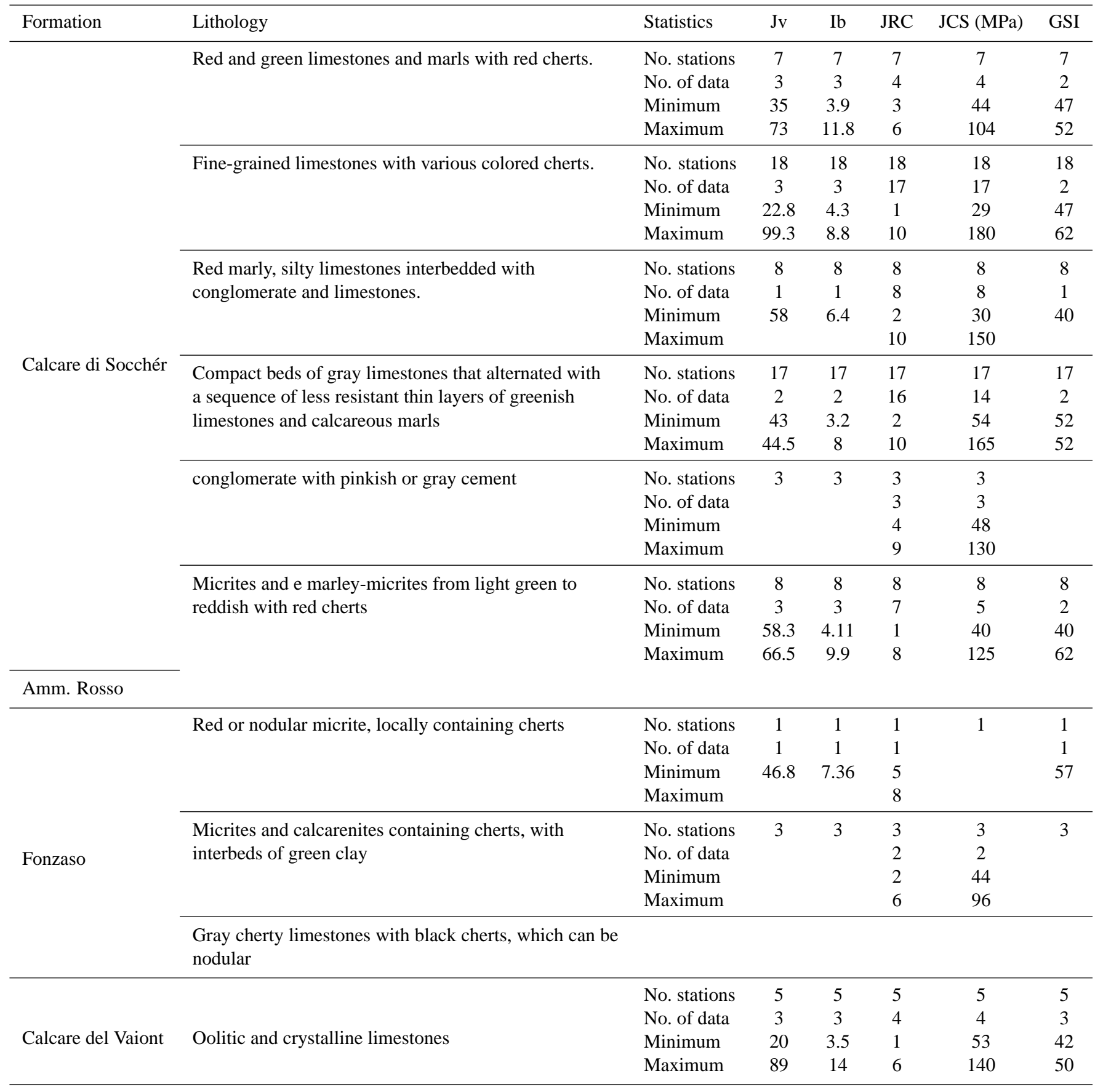

limitation in available data is given in Table 1. Values and relationships between distinctive properties, such as the Volumetric Joint Count (Jv) and Block Size Index (Ib) (Cai et al., 2004; Kalenchuk et al., 2006; Palmström, 1996, 2005), can aid in defining lithotechnical units, while the Joint Roughness Coefficient (JRC), the Joint Compressive Strength (JCS) and the Geological Strength Index (GSI) are necessary for continuum or discontinuum modelling of the rock slope. However, the number of data available for each geological formation are insufficient to obtain spatial distributions at a statistically significant level, thus, making it currently impossible to subdivide the rock masses involved in the event into realistic geomechanical units. 
A re-evaluation of the failure mechanism of the Vaiont landslide requires further research on still poorly constrained features of the area with a collection of additional spatial data. Field surveys, tests and analyses are in progress in order to improve the geodatabase. Field investigations are being extended into areas peripheral to the landslide, in order to provide a more comprehensive characterisation of the rock masses in the pre- and post-event conditions; this will form the foundation for 2-D/3-D numerical simulation using continuum and discontinuum numerical codes.

Surface based techniques, such as the comparison of preand post-event DEMs, and acquisition of deep level seismic tomography, to investigate the 3-D distribution of different rock masses, will allow improved definition of the displacement field of the landslide body.

Completing the geodatabase and performing the reevaluation of the Vaiont landslide will represent an important contribution to a more comprehensive understanding of large rock slope instabilities.

Acknowledgements. This research was financially supported by the University of Padova, research projects CPDA085240 (Principal investigator: Mario Floris, Department of Geosciences) and GEORISKS (Principal investigator: Rinaldo Genevois, Department of Geosciences).

Edited by: D. Giordan

Reviewed by: F. M. Guadagno and another anonymous referee

\section{References}

Broili, L.: New knowledge on the geomorphology of the Vaiont Slide slip surfaces. Rock Mechanics \& Eng. Geol., J. Int. Soc. Rock Mechanics., V(1), 38-88, 1967.

Cai, M., Kaiser, P. K., Uno, H., Tasaka, Y., and Minami, M.: Estimation of rock mass deformation modulus and strength of jointed hard rock masses using the GSI system. Int. J. Rock Mech. Mining Sci., 41, 3-19, 2004.

Caloi, P.: L'evento del Vajont nei suoi aspetti geodinamici, Ist. Naz. Geofisica, Roma, 1966.

Chacón, J., Irigaray, C., Fernandez, T., and El Hamdouni, R.: Engineering geology maps: landslides and geographical information systems, B. Eng. Geol. Environ., 65, 341-411, 2006.

Derron, M.-H., Jaboyedoff, M., and Blikra, L. H.: Preliminary assessment of rockslide and rockfall hazards using a DEM (Oppstadhornet, Norway), Nat. Hazards Earth Syst. Sci., 5, 285-292, 2005 ,

http://www.nat-hazards-earth-syst-sci.net/5/285/2005/.

Genevois, R. and Ghirotti, M.: The 1963 Vaiont Landslide - Giornale di Geologia Applicata, I, 41-53, 2005.

Giardino, M., Giordan, D., and Ambrogio, S.: G.I.S. technologies for data collection, management and visualization of large slope instabilities: two applications in the Western Italian Alps, Nat. Hazards Earth Syst. Sci., 4, 197-211, 2004,

http://www.nat-hazards-earth-syst-sci.net/4/197/2004/.

Giudici, F. and Semenza, E.: Studio geologico del serbatoio del Vajoint. Unpublished report for S.A.D.E., Part A: 21 pp, text, Part B: 68 photos with discussions, 42 pp, Venezia, Italy, 1960.
Hendron, A. J. and Patton, F. D.: The Vaiont Slide, a Geotechnical Analysis Based on New Geologic Observations of the Failure Surface. I, II, Technical Report GL-85-5, US Army Eng. Waterways Experiment Station, Vicksburg, MS, 1985.

Hendron, A. J. and Patton, F. D.: A geotechnical analysis of tha behavior of the Vaiont slide, Civil Engineering Practice Fall, 65130, 1986.

Jaboyedoff, M., Metzger, R., Oppikofer, T., Couture, R., Derron, M.-H., Locat, J., and Turmel, D.: New insight techniques to analyze rock-slope relief using DEM and 3D-imaging cloud points: COLTOP-3D, Rock mechanics Vol. 1: Meetings Society's Challenges and demands, chap. 7, 61-68, edited by: Eberhardt, E., Stead, D., and Morrison, T., 2007.

Jaboyedoff, M., Couture, R., and Locat, P.: Structural analysis of Turtle Mountain (Alberta) using digital elevation model: toward a progressive failure, Geomorphology, 103, 5-16, 2009.

Kalenchuk, K. S., Diederichs, M. S., and McKinnon, S.: Characterizing block geometry in jointed rock masses, Int. J. Rock Mech. Mining Sci., 43(8), 1212-1225, 2006.

Kilburn, C. R. J. and Petley, D. N.: Forecasting giant, catastrophic slope collapse: lessons from Vajont, Northern Italy, Geomorphology, 54(1-2), 21-32, 2003.

Müller, L.: The Rock Slide in the Vaiont Valley, Rock Mech. Eng. Geol., 2, 148-212, 1964.

Müller, L.: The Vaiont catastrophe - A personal review, in: Dam Failures, edited by: Leonards, G. A., Eng. Geol., 24(1-4), 423444, 1987a.

Müller, L.: The Vaiont Slide, in: Dam Failures, edited by: Leonards, G. A., Eng. Geol., 24(1-4), 513-523, 1987 b.

Nonveiller, E.: Vaiont Slide - Influence of Frictional Heat on Slip Velocity, in: Proceedings of the meeting on the 1963 Vaiont landslide, edited by: Semenza, E. and Melidoro, G., IAEG Italian Section, University of Ferrara, Ferrara 1986, 1, 187-197, 1992.

Palmström, A.: Characterizing rock masses by the RMi for use in practical rock engineering, Tunn. Undergr. Sp. Tech., 11(2), 175$188,1996$.

Palmström, A.: Measurements of and correlations between block size and rock quality designation (RQD), Tunn. Undergr. Sp. Tech., 20, 362-377, 2005.

Rossi, D. and Semenza, E.: Carte geologiche del versante settentrionale del M. Toc e zone limitrofe, prima e dopo il fenomeno di scivolamento del 9 ottobre 1963, Scala 1:5000, Ist. Geologia Università di Ferrara, 2 Maps, 1965.

Selli, R., Trevisan, L., Carloni, C. G., Mazzanti, R., and Ciabatti, M.: La Frana del Vajont, Giornale di Geologia, serie 20, XXXII(I), 1-154, 1964.

Semenza, E.: Sintesi degli studi geologici sulla frana del Vaiont dal 1959 al 1964, Mem. Museo Tridentino Sc. Nat., 16, 1-52, 1965.

Semenza, E.: La storia del Vaiont raccontata dal geologo che ha scoperto la frana. Tecomproject Ed., Ferrara, Italy, 2000.

Semenza, E. and Ghirotti, M.: History of 1963 Vaiont Slide. The importance of the geological factors to recognise the ancient landslide, B. Eng. Geol. Env., 59, 87-97, 2000.

Skempton, A. W.: Bedding-plane slip, residual strength and the Vaiont Landslide, Géotechnique, XVI(1), 82-84, 1966.

Tika, Th. E. and Hutchinson, J. N.: Ring shear tests on soil from the Vaiont landslide slip surface, Geotechnique, 49(1), 59-74, 1999. 